\title{
Religión e identidad. La amenaza del Estado Islámico en Irak y Siria*
}

\author{
Guillermo OSPINA MORALES**
}

Artículo recibido: 30 de octubre de 2017

Artículo aceptado: 13 de diciembre de 2017

Doi: http://dx.doi.org/10.12804/revistas.urosario.edu.co/desafios/a.6206

Para citar este artículo: Ospina Morales, G. (2019). Religión e identidad. La amenaza del Estado Islámico en Irak y Siria. Desafíos, 31(1), 237-271. Doi: http://dx.doi.org/10.12804/ revistas.urosario.edu.co/desafios/a.6206

\section{Resumen}

Las acciones del Estado Islámico en el norte de Irak representaron una amenaza existencial para los diferentes grupos societales que habitaban los territorios que quedaron en manos del autodenominado califato. Sin embargo, sus acciones no son violencia sin sentido, irracionalidad o sevicia. Estas son parte de la concepción salafista, la cual señala que el islam se encuentra en peligro existencial por lo que la violencia contra las minorias es considerada necesaria para la defensa del monoteísmo (tawhid) y para la lucha contra el politeismo (shirk) y los infieles (kuffar). De este modo, el presente articulo analiza cómo la securitización de la religión que realiza el Estado Islámico representa una amenaza para los grupos minoritarios en Irak y Siria.

Palabras clave: securitización, Estado Islámico, salafismo, Irak, Siria.

\footnotetext{
* Una versión preliminar de este artículo fue presentada en el V Congreso de RedIntercol, celebrado en Bogotá entre el 11 y el 13 de octubre de 2017. Asimismo, presenta algunas de las conclusiones de la tesis de maestría en Estudios Políticos e Internacionales titulada "El Estado Islámico y la seguridad societal: sectarismo y violencia intercomunitaria en Irak y Siria".

** Magíster en Estudios Políticos e Internacionales de la Universidad del Rosario. Licenciado en Educación Básica con Énfasis en Ciencias Sociales de la Universidad Distrital. Correo electrónico: guillermo.ospinam@gmail.com. ORCID: http://orcid.org/0000-0001-6159-5667
} 


\title{
Religion and Identity. The Threat of the Islamic State in Iraq and Syria
}

\begin{abstract}
The Islamic State's actions in northern Iraq represented an existential threat to the different societal groups that inhabited the territories that were held by the self-proclaimed caliphate. However, its actions are not senseless violence, irrationality or brutality. These are part of the Salafist conception, which indicates that Islam is in existential risk, therefore, violence against minorities is considered necessary to defend monotheism (tawhid) and the fight against polytheism (shirk) and the infidels (kuffar). The article analyzes how the securitization of religion carried out by the Islamic State represents a threat to minority groups in Iraq and Syria.
\end{abstract}

Keywords: Securitization, Islamic State, Salafism, Iraq, Syria.

\section{Religião e identidade. A ameaça do Estado Islâmico no Iraque e na Síria}

\begin{abstract}
Resumo
As ações do Estado islâmico no norte do Iraque representaram uma ameaşa existencial para os diferentes grupos societais que habitavam os territórios que ficaram em mãos do autodenominado Califado. No entanto, suas ações não são violência sem sentido, irracionalidade ou sevícia. Estas são parte da concepscão salafista, a qual assinala que o islão se encontra em perigo existencial, pelo que, a violência contra as minorias é considerada necessária para a defesa do monoteísmo (tawbid) e a luta contra o politeísmo (shirk) e os infieis (kuffar). Deste modo, o presente artigo analisa como a securitização da religião que realiza o Estado islâmico representa uma ameaça para os grupos minoritários no Iraque e na Síria.
\end{abstract}

Palavras-chave: securitização, Estado Islâmico, salafismo, Iraque, Síria. 


\section{Introducción}

Entre junio y septiembre de 2014, el Estado Islámico avanzó sobre la provincia de Nínive (norte de Irak) para consolidar el control sobre los territorios del recién autoproclamado califato. Así, tras la toma de Mosul, se pondría en marcha una campaña sistemática para erradicar la presencia de todo aquello que fuese considerado no islámico. De este modo, a través de la conversión forzada, la destrucción de propiedades civiles y religiosas, los asesinatos masivos, la violencia sexual y el desplazamiento se buscaría eliminar todo rastro de aquellas minorías que habitaban en la región.

No obstante, para cristianos ${ }^{1}$ y yazidíes la amenaza sería mayor. En primer lugar, porque ambas comunidades concentraban la mayoría de su población en la provincia de Nínive, ya que esta región es considerada su tierra ancestral. Segundo, el avance del Estado Islámico representaba un riesgo para la totalidad de su población, puesto que, como minorías étnico-religiosas, no poseían miembros musulmanes (sunnitas) ${ }^{2}$. Tercero, las acciones del Estado Islámico tuvieron como objetivo eliminar toda manifestación de su identidad, tanto materialmente/ físicamente como ontológicamente, dado que tolerar su existencia es incompatible con la proclamación del califato y con el retorno a la versión prístina del islam, fundamentada en el estricto cumplimiento de la doctrina del tawbid (monoteísmo). Por lo tanto, estas comunidades fueron llevadas al borde de la extinción como grupo societal.

De esta manera, para comprender la dinámica de seguridad de las comunidades minoritarias es necesario recurrir al concepto de seguridad societal, el cual señala que la supervivencia de una sociedad depende del mantenimiento de unas ideas y prácticas que permiten que los

\footnotetext{
1 El cristianismo en Irak comprende varios grupos étnicos, entre ellos, armenios, turcomanos y circasianos. Sin embargo, la gran mayoría de miembros de la comunidad cristiana corresponde a los asirios (caldeos, caldeo-asirios o siriacos).

2 En Badoush, Sinjar y Tal Afar, el Estado Islámico separó y colocó a salvo a los miembros sunnitas de las minorías étnicas shabak y turcomana del resto de pobladores (Amnistía Internacional, 2014; Human Rights Watch, 2014; Minority Rights Group International, 2015).
} 
individuos se autoidentifiquen con esta, por lo que impedir o afectar los patrones normales de transmisión de la identidad (étnica, lingüística, religiosa) hace peligrar la existencia de las comunidades (Buzan, Waever \& de Wilde, 1998). Por consiguiente, las acciones del Estado Islámico atacaron los mecanismos de reproducción de la identidad y la fábrica social de las minorías y constituyeron así una amenaza existencial.

Sin embargo, el actuar de los hombres de al-Baghdadi no corresponde a una violencia sin sentido, a la irracionalidad o a la sevicia. Por el contrario, sus acciones buscan el retorno a la versión más pura del islam para defender la "verdadera religión" y transformar la realidad del pueblo musulmán que ha sido humillado y subyugado por lo infieles (Occidente).

Para los grupos salafistas-yihadistas, como el Estado Islámico, esta situación es resultado de la tolerancia o aceptación de prácticas no islámicas y del alejamiento del ejemplo del Profeta y de los Rashidun ${ }^{3}$, por lo que volver al islam que practicaban los píos predecesores (salafi manhaj) es el camino a seguir para recuperar la gloria del pueblo musulmán. No obstante, esto va más allá del reconocimiento de la unicidad de Allah (tawhid), expresado en la profesión de fe (shahada ${ }^{4}$ ), primer pilar de islam ${ }^{5}$. El tawhid, como fundamento de la doctrina salafista, exige la rigidez tanto en la creencia (aqida) como en el comportamiento del musulmán.

Por lo anterior, para comprender la amenaza del Estado Islámico es posible considerar metodológicamente al salafismo como una forma

\footnotetext{
3 Los cuatro primeros califas: Abu Bakr al-Siddiq, Umar ibn al-Khattab, Uthman ibn Affan y Ali ibn Abi Talib. Sus gobiernos se consideran como la época de mayor esplendor del islam, lo cual se debe a su cercanía con el Profeta y a la guía proveniente del él (Esposito, 2003).

4 La profesión de fe, "no hay más Dios que Allah y Mahoma es su profeta". Esta unicidad de Dios, es expresada de tres formas: el reconocimiento de la omnipotencia de Dios (tawhid al-rububiyya); la unicidad de la divinidad de Dios, que implica la adoración únicamente de Él (tawhid al-ulubiyya); y la unicidad de los nombres y atributos de Dios (tawbid al-asma wa'l-sifat) a través de la aceptación literal de los nombres y atributos de Allah (Meijer, 2010, p. 39). Esta división se atribuye a Ibn Taymiyyahh.

5 Los otros pilares son: la oración (salat), la limosna (zakat), el ayuno durante el mes del Ramadán (sawm) y la peregrinación a la Mecca (bayy).
} 
de securitización de la religión, al elaborar un discurso que establece que el islam se encuentra en peligro existencial debido al alejamiento del tawhid. Asimismo, gracias a la relación entre la acción y la creencia, señala la frontera entre los infieles (kuffar) y el islam (Helfont, 2009, p. 5; Olidort, 2015, p. 5), en otras palabras, identifica al enemigo al definir quién es el buen musulmán, el apóstata (murtadd) y el infiel (kafir). Por último, considera que la yihad y la aplicación de la sharia son el camino para la purificación del islam, lo que, en términos de la securitización, constituyen las medidas extraordinarias.

No obstante, la securitización de la religión posee ciertas particularidades frente a la propuesta original de la Escuela de Copenhague, a saber, que el discurso securitizador religioso se caracteriza por ser, simultáneamente, tanto ofensivo como defensivo, ya que la defensa del objeto referente ${ }^{6}$ no se origina en función de la amenaza, sino que parte de una serie de imperativos religiosos que buscan alcanzar un estado u orden existente de acuerdo a una cosmología religiosa, por lo que las amenazas se toman como obstáculos que deben ser superados para lograrlo (Sheikh, 2014, p. 269). Esta secuencia es visible en la concepción salafista del islam que considera que para la defensa del tawhid es necesaria la lucha incesante contra el politeísmo (shirk), los infieles (kuffar) y los apóstatas (murtadd), lo que implica tanto atacar a las minorías y al chiismo como la guerra contra Occidente y los gobiernos de Medio Oriente.

En segundo lugar, el discurso salafista integra elementos políticos, religiosos e identitarios, así, la securitización del islam puede ser analizada de formar intersectorial (de acuerdo a los sectores de la seguridad identificados por Buzan, et al., 19987). Por lo tanto, las acciones del Estado Islámico repercuten tanto en la seguridad de las comunidades como en la de los Estados. Por último, la defensa de la religión,

\footnotetext{
6 Aquello cuya existencia se encuentra en peligro y que por ser considerado valioso debe ser protegido a través de unas medidas extraordinarias para lograrlo de forma efectiva.

7 Se identifican cinco sectores: militar, político, económico, societal y ambiental (cf. Buzan, et al., 1998). No obstante, algunos autores han explorado la religión como un nuevo sector de la seguridad. De esta manera, Laustsen \& Waever (2003) y Sheikh (2014) proponen, respectivamente, a la fe y a la doctrina como los objetos referentes para un nuevo sector que aborde fenómenos como el activismo religioso y el fundamentalismo.
} 
a partir del discurso salafista, implica el desarrollo de una identidad —el "islam verdadero", el pueblo sunnita, el "buen musulmán”- y se contrapone existencialmente a la presencia de otras religiones y al orden político existente que ha dividido la umma.

Por lo anterior, para comprender el discurso del Estado Islámico y cómo este justifica sus acciones, se abordan diferentes publicaciones distribuidas a través de internet, como videos, declaraciones, la revista Dabiq y algunos documentos oficiales que han sido filtrados. No obstante, producto de las limitaciones relacionadas con el idioma, las principales fuentes primarias corresponden a los contenidos producidos en inglés, por lo tanto, se recurre a diversas fuentes documentales secundarias como informes de organizaciones humanitarias, artículos periodísticos y noticias.

\section{El Estado Islámico y la Escuela de Copenhague}

La seguridad societal y la securitización son, tal vez, los aportes más importantes de la Escuela de Copenhague a los estudios de seguridad, desarrollados en medio del denominado proceso de broadening y deepening. Estos han cuestionado la naturaleza objetiva de las amenazas de las tradiciones clásicas y han permitido abordar nuevas temáticas dentro de la agenda de seguridad, entre ellas, la identidad y la religión.

De esta manera, la seguridad societal y su desarrollo conceptual son herramientas epistemológicas importantes para la compresión del conflicto en Irak y Siria, en el que los diferentes grupos societales (minorías, sectas, tribus y clanes) que habitan estos territorios se encuentran en riesgo existencial, producto de la desestabilización de los Estados y el surgimiento de diferentes grupos armados; así, las identidades, y su defensa, se han convertido en un factor determinante de la dinámica del conflicto.

La seguridad societal considera la sociedad como objeto referente cuya supervivencia depende de la capacidad de mantener los mecanismos que permiten que los individuos se identifiquen como miembros 
de esta (Buzan, et al., 1998, p. 212); en otras palabras, su existencia precisa del sostenimiento de una identidad, definida como las ideas y prácticas que posibilitan que los individuos se reconozcan como parte de un grupo gracias a la definición de un "Otro" y un "Nosotros" (Buzan, et al., 1998, p. 119).

Por su parte, la securitización presenta un enfoque constructivista para la identificación de las amenazas, en este caso, con relación a una identidad. De esta manera, un actor — los líderes políticos, religiosos, tribales o pequeños grupos-identifican y presentan las amenazas a las que está sometida alguna identidad frente a una audiencia determinada; así, se aprueban (o no) unas medidas o acciones extraordinarias para contrarrestarlas.

No obstante, la intensidad de las amenazas a la seguridad societal variará de acuerdo con la vulnerabilidad que se posea en determinado aspecto, es decir, si elementos como el territorio, la lengua, la religión, las costumbres, entre otros, son la base sobre la cual se fundamenta una identidad. De esta manera, Buzan, et al. (1998, pp. 124-126) identifican cuatro tipos de amenazas: la migración ${ }^{8}$, la competencia vertical ${ }^{9}$, la competencia horizonta ${ }^{10}$ y la despoblación ${ }^{11}$. La relevancia de estas dependerá del contexto en el cual se desarrollen. En consecuencia, la migración será mayor en aquellas zonas que posean una alta dinámica vecinal y/o intrarregional; la competencia vertical será más intensa en contextos en los que exista un proyecto secesionista o integracionista; mientras que la competencia horizontal ocurrirá de manera variada y

\footnotetext{
8 Se presenta cuando una comunidad es afectada en su identidad debido a los cambios en la composición de la población, producto de la llegada de nuevos habitantes que poseen otras identidades y que sobrepasan, diluyen o influyen a la población original.

9 La competencia vertical se presentará cuando determinada identidad cambia su concepción, bien sea porque hará parte de una identidad más amplia o más pequeña, como en el caso de los proyectos integracionistas o secesionistas.

10 La competencia horizontal ocurrirá cuando existan minorías o Estados pequeños que se encuentren amenazados por la influencia de una cultura mayoritaria, por ejemplo, el temor de los países musulmanes a la occidentalización.

11 Esta última amenaza es someramente mencionada por Buzan, et al. al señalar que, evidentemente, la identidad de una sociedad se ve amenazada por la desaparición física de sus miembros, bien sea por exterminio, enfermedades o desastres naturales.
} 
a diferente nivel, ya sea cuando existan minorías o Estados pequeños que se encuentran amenazados por una cultura mayoritaria.

Por lo tanto, como se observa en la tabla 1, las minorías - especialmente en Irak - han enfrentado las diferentes amenazas que ha establecido la Escuela de Copenhague para la seguridad societal, por lo que el riesgo de desaparición de estas comunidades es alto. Si bien su situación ha sido precaria desde la caída del régimen de Saddam Husein, en 2003, la proclamación del califato constituye el mayor riesgo existencial que han afrontado hasta el momento.

De este modo, a través de la violencia sexual, las ejecuciones masivas, la conversión forzada, la destrucción de sitios religiosos y el desplazamiento el Estado Islámico buscó erradicar la identidad y, con ello, la presencia de las minorías de los territorios bajo su control. Sin embargo, estos hechos eran consecuentes con la concepción salafista del islam, la cual constituye el corazón de su ideología.

Tabla 1. La seguridad societal de las minorías

\begin{tabular}{|l|l|}
\hline \multicolumn{2}{|c|}{ Amenazas a la seguridad societal de las minorías } \\
\hline Migración & $\begin{array}{l}\text { Las minorías se han visto obligadas a abandonar sus tierras } \\
\text { ancestrales tanto por la violencia en su contra, como por la } \\
\text { expulsión de sus territorios. Aunque durante muchos años } \\
\text { soportaron el acoso, la intimidación y la persecución de células } \\
\text { islamistas que pretendían forzarlos a dejar las ciudades, el } \\
\text { avance del Estado Islámico obligó al abandono total —por la } \\
\text { fuerza o por temor- de aquellos sitios que habían habitado } \\
\text { durante milenios. }\end{array}$ \\
\hline Competencia & $\begin{array}{l}\text { El Estado Islámico ha utilizado la violencia armada y sexual } \\
\text { para fomentar la conversión forzada de las minorías con el fin } \\
\text { de asimilarlas dentro del califato. }\end{array}$ \\
\hline Corizontal & $\begin{array}{l}\text { La identidad de la población minoritaria es desconocida y } \\
\text { erradicada dentro del califato, reivindicando la identidad } \\
\text { musulmana. Así, el Estado Islámico ha reclamado propiedad } \\
\text { sobre los bienes (desde objetos personales y vehículos hasta } \\
\text { edificios civiles y religiosos) de las minorías y ha fomentado la } \\
\text { conversión forzada. }\end{array}$ \\
\hline Despoblación & $\begin{array}{l}\text { Miles de miembros de las minorías han sido asesinados desde } \\
\text { 2003 y, especialmente, desde la proclamación del califato. }\end{array}$ \\
\hline
\end{tabular}

Fuente: Elaboración propia. 
Las acciones del Estado Islámico han sido justificadas como parte del actuar del "buen musulmán" para defender la "religión verdadera" de la idolatría y el politeísmo. Por esta razón, la amenaza del Estado Islámico se origina en el discurso salafista que le brinda las bases teológicas al señalar que existe una guerra en contra del islam, lo que constituye un discurso securitizador de la religión.

\section{La "tradición" salafista y la formación del discurso religioso}

El discurso salafista no ha aparecido súbitamente, este se ha desarrollado a través del tiempo y ha ido integrando varios elementos que han permitido la politización y la securitización de la religión. Así, sucesos como el colonialismo europeo, la Revolución de Irán, la Guerra de Irak y la Primavera Árabe, por mencionar algunos, han sido escenarios para el desarrollo y la expansión del discurso salafista en la región. Por lo tanto, el primer paso para comprender el salafismo contemporáneo, en la versión más extremista del Estado Islámico, exige abordar, al menos brevemente, los elementos de la "tradición" salafista y cómo esto conlleva a una defensa activa de la religión.

De esta manera, es posible identificar cuatro periodos en el desarrollo del discurso salafista: el origen doctrinal en siglo XVIII, la herencia del imperialismo británico y el movimiento panislamista, el renacimiento en la década de los ochenta, y la invasión norteamericana a Irak en 2003. En estos contextos han aparecido diferentes personajes como Muhammad ibn Abd-al-Wahhab, Hasan al-Banna, Sayyid Qutb e, inclusive, Abu Musab al-Zarqawi, quienes han brindado importantes aportes teológicos, políticos y estratégico-militares para la realización y materialización de los fundamentos doctrinales del salafismo.

En primer lugar, el salafismo se origina en la península arábiga en el siglo XVIII, en medio de la aparición de varios movimientos revivalistas que buscaban tanto revitalizar como purificar el islam de diferentes prácticas religiosas que observaban entre la población. Así, Muhammad ibn Abd-al-Wahhab daría continuidad a las corrientes 
literalistas y escrituralistas que habían surgido de los debates teológicos del siglo $\mathrm{IX}^{12}$, en especial, a la Escuela Hanbali y al pensamiento del jurista medieval Taqin al-Din Ahmad Ibn Taymiyyah, quien señalaba que el Corán debía ser entendido de forma literal dada su naturaleza divina, por lo que era inaceptable una interpretación de la escrituras.

A partir de estas fuentes, al-Wahhab da origen al discurso salafista a través de un movimiento que vendría a ser conocido como wahabismo ${ }^{13}$ y que tenía como principal objetivo corregir la forma cómo el musulmán entiende y práctica su fe (Olidort, 2015, p. 5), es decir, se trataba del retorno al islam practicado por Mahoma, por sus compañeros y por la primera generación de musulmanes, lo que en árabe se expresa en el término al-salaf al-salib (Helfont, 2009; Meijer, 2010; Bunzel, 2015; Olidort, 2015).

La lectura que hace el salafismo de la realidad de la comunidad musulmana es pesimista (Meijer, 2010, p. 38): se encuentra en estado de decadencia debido al alejamiento del ejemplo del Profeta y a la aceptación o tolerancia de prácticas no islámicas. De este modo, la comunión entre el hanbalismo y el wahabismo establecía los criterios para llegar a ser considerado un "verdadero musulmán”. Por tanto, para al-Wahhab e Ibn Taymiyyah, la shahada era insuficiente para serlo y debería ser acompañada de la acción contra el mal, la idolatría y los infieles.

Así, al-Wahhab pregonó la necesidad de eliminar toda práctica propia de la época preislámica ( yabiliyyab) como la adoración de tumbas, san-

\footnotetext{
12 Este consistía en la disputa teológica entre las posturas literalistas y racionalistas del Corán. La primera de estas correspondía a la escuela Alh al-Hadith (el pueblo del Hadiz), representada por Ahmad Ibn Hanbal. Por su parte, la escuela Al-Mu'tazila — proveniente del término ittazala (separación)_, encabezada por Wasil ibn Ata, apoyaba la división del Corán en dos partes, una literal y otra sujeta a la interpretación (Olidort, 2015, pp. 7-8).

13 Cabe mencionar que existe una diferencia entre el wahabismo y el salafismo, el primero está directamente relacionado con el Estado saudita y la escuela Hanbali, mientras que el salafismo rechaza tanto a los Estados como a las escuelas jurídicas musulmanas (Olidort, 2015, p. 8). Sin embargo, los wahabitas ven con beneplácito ser referenciados como salafistas, evitando ser asociados con las enseñanzas de un hombre y siendo reconocidos por su seguimiento del ejemplo del Profeta (Helfont, 2009, p. 2).
} 
tos, creencias en objetos de buena suerte y la hechicería. Corregir estas desviaciones exigía para el musulmán el rechazo de toda innovación (bid'ah) y el seguimiento estricto — literal — del Corán (kitab) y de la sunna $b^{14}$, y sería evidente en el comportamiento del individuo que debía guiarse por los conceptos de al-wala' wa al-bara' (lealtad a Allah y repudio o disociación de los infieles), al-amr bi'l-ma'ruf wa'l-naby'an al-munkar (disfrutar o hacer lo correcto y prohibiendo lo incorrecto) y a la yihad ${ }^{15}$. De esta manera, se lograría la purificación del islam tras la eliminación de toda forma de bid'ah, kafir y shirk.

Para el salafismo, aquellos que toleran y siguen aquellas prácticas que no son acordes con el tawhid no deberían ser considerados musulmanes. De esta manera, la acusación de takfir ${ }^{16}$ recaía, en especial, sobre la población chiita que fundamenta gran parte de su fe en la visita de tumbas — como en la ciudad de Qom y Nayaf — y en la exaltación de la muerte. Por ejemplo, la Ashura, su principal festividad, consiste en la peregrinación a la tumba del Iman Husayn Ibn Ali, nieto de Mahoma, y muerto en la Batalla de Karbala en el año 680. Así, el antichiismo será una característica de gran parte del salafismo.

14 El término puede traducirse como conducta, estilo de vida, hábito o forma de actuar, y debe ser acorde al ejemplo del Profeta y sus primeros seguidores, que se encuentra ilustrado en una colección de enseñanzas, dichos y aprobaciones. Estos son el fundamento de la legislación islámica y de la distinción entre lo aprobado y lo reprochable en el islam (Esposito, 2003).

15 Su definición corresponde al esfuerzo que debe hacer todo musulmán en defensa de la fe, es decir, la lucha contra el mal, que involucra tanto el aspecto interno (espiritual) como la "guerra santa". Esta última acepción ha sido utilizada por varios analistas y, en general, no-musulmanes para señalar al islam como una religión violenta, una concepción influenciada por el tiempo de las cruzadas. Sin embargo, la yihad, entendida como guerra, puede ser considerada de dos maneras: yihad ofensiva y yihad defensiva. La primera sería una guerra misionera que se presenta en tiempos en que la religión se está expandiendo y en que los musulmanes se encuentran en posición de poder, por tanto, es un deber colectivo llevado a cabo por un gobernante musulmán y sus ejércitos (Helfont, 2009, p. 42). Por su parte, la yihad defensiva se realiza cuando el islam es amenazado o atacado; es, entonces, un deber individual que exige la participación de cada musulmán en la lucha, involucrando a toda la umma en la defensa, tanto de la fe, como de las tierras del islam (Helfont, 2009, p. 43).

16 Es el pronunciamiento o la práctica de excomunión que realiza un musulmán sobre otro al señalarlo de infiel y apóstata. Este término deriva de la palabra kafir, que significa infiel o "aquel que se niega a aceptar la revelación divina” (Esposito, 2003). 
Un último aspecto a destacar del salafismo primigenio es la legitimidad de los gobiernos. El término taghut ${ }^{17}$ ha sido utilizado para cuestionar a los gobernantes de los países musulmanes, avalando la yihad contra ellos. Así, Ibn Taymiyyah defendía la lucha contra los mandatarios que, proclamándose musulmanes, no aplican la sharia. Sin embargo, es importante destacar que él vivió en la época de la invasión mongola al Imperio abasí, por lo que, a pesar de la conversión de los mongoles al islam, rechazaba su autoridad ya que gobernaban de acuerdo a la ley mongola yassa — decretada por Gengis Khan-, en vez de la sharia. Este contexto es importante para comprender porque Ibn Taymiyyah autorizaba la guerra en contra de otros musulmanes (takfir), así como la necesidad de purificar el islam de la ignorancia pagana (yahiliyyah).

El segundo periodo de desarrollo del discurso salafista está enmarcado por las consecuencias de la Primera Guerra Mundial y el fin del Imperio otomano. De este modo, el encuentro del pensamiento occidental con el islam, producto del dominio colonial, contribuiría al desarrollo del panislamismo y a la politización de la religión (islam político). Por consiguiente, la purificación del islam profesada por el salafismo se convertiría en un objetivo político para recuperar las tierras del islam (dar al-Islam) de los europeos, unificar la umma y formar un Estado islámico (al-Dawla $)^{18}$ — con miras a restaurar el califato- dando origen a movimientos como la Hermandad Musulmana y Jamaat-eIslami — ambos fundados en Egipto_- los cuales encontraban en la yihad y en la reislamización de la sociedad los métodos para lograrlo (El-Affendi, 2010, p. 30-31; Helfont, 2009, p. 9-10).

\footnotetext{
17 Falso dios o falso ídolo. Se relaciona con aquellos tiranos que rechazan o desconocen el poder de Allah, no gobiernan de acuerdo a su ley sagrada y oprimen a su pueblo (Esposito, 2003).

18 La umma es la institución en la cual reside la soberanía, sin embargo, esta es abstracta, casi en el sentido de ser una "comunidad imaginada". No obstante, la umma posee una dimensión vinculada a la existencia de un territorio islámico (dar al-islam), un lugar en el cual la comunidad goza de paz y seguridad, y cuyo gobierno actúa de acuerdo a la sharia y al Corán. Por tanto, la comunidad de creyentes requiere tanto de un territorio como de un gobierno. En contraposición a dar al-Islam, existen los territorios hostiles, dar al-harb, de los cuales lo musulmanes deben emigrar y hacerles frente en caso de ser necesario (El-Affendi, 2010, pp. 29-30).
} 
La Hermandad Musulmana, fundada en 1928 por Hasan al-Banna, considera al islam la solución a todos los problemas de la sociedad musulmana, desde lo político hasta lo social o lo económico (Helfont, 2009, p. 11). De esta manera, la religión se convertía en la herramienta fundamental para superar el estado de decadencia y sometimiento ante las potencias europeas. No obstante, las posiciones más radicales surgirían de la defensa de la causa palestina y de la oposición al armisticio árabe-israelí (1949). Esto conllevaría al enfrentamiento con el gobierno egipcio, por lo que la Hermandad sería declarada ilegal, precipitando el arresto de sus principales miembros y el asesinato de su líder, Hasan al-Banna (1949).

Así, ante la desaparición de los fundadores, aparecieron nuevos líderes más radicales e influenciados por las ideas de al-Wahabb e Ibn Taymiyyah. Entre ellos, el más importante es Sayyid Qutb, quien estableció varios de los elementos fundamentales del salafismo yihadista contemporáneo. El pensamiento "qutbista" retomaba del salafismo "tradicional" la importancia de la acción para hacer frente al enemigo y defender la fe, por lo que la creación de un Estado islámico (al-Dawla) sería posible únicamente a través de la yihad y de la violencia en contra de los gobiernos de la época. Igualmente, Qutb consideraba al islam la fuente de toda identidad política, es decir, el sistema islámico era la nación, la patria y el pueblo del creyente; por lo tanto, se debía rechazar todo tipo de modelo nacionalista, socialista o partido político, lo que era considerado un tipo de innovación que no es al Corán y a la sunnah (Helfont, 2009, p. 16; Olidort, 2015, p. 8).

Aunque Qutb no poseía un amplio conocimiento religioso, los conceptos de hakkimiyyah (soberanía de Allah) y yahiliyyah (era preislámica) se ajustaban a la defensa del tawhid (Meijer, 2010, p. 52). Estos conceptos son relacionados de forma causal, de manera que el estado de yabiliyyah - considerado por Qutb una condición espiritual y, por lo tanto, atemporal— de las sociedades musulmanas es resultado de conferir la soberanía a gobernantes que permiten y practican ideas no islámicas que contaminan la religión (Helfont, 2009, p. 17). De esta manera, la soberanía se concibe como un atributo exclusivo de Dios que se materializa a través de la aplicación de la sharia y del gobierno de hombres 
píos. Este modelo permitiría la unificación de la umma y la formación de un Estado Islámico.

Igualmente el takfirismo, presente en las ideas de Ibn Taymiyyah y alWahhab, confluía en el pensamiento de Qutb (Helfont, 2009, p. 17), por lo que todos aquellos líderes musulmanes que no gobernaban bajo la sharia (taghut) y los musulmanes que continuaran en yahiliyyah podrían ser considerados infieles y apóstatas. De esta manera, ante la pérdida de dar al-Islam, la yihad es realizada contra el mal representado en los gobernantes impíos y en el imperialismo que ocupa las tierras islámicas, por lo que el muyabidín ${ }^{19}$ es considerado un libertador (Helfont, 2009, p. 44).

Este discurso será el legado del "qutbismo" para el renacimiento del salafismo en la década de los ochenta que se inauguraría con tres hechos que manifestaban el crecimiento del activismo religioso: la Revolución de Irán, la toma de la Gran Mezquita de la Meca y la invasión soviética de Afganistán. Cada uno de estos inspiraría la creación de diferentes grupos (armados y/o terroristas) que caracterizarían el tercer periodo del desarrollo del salafismo.

Afganistán sería el punto de encuentro de "qutbistas" como alZawahiri y wahabitas como Osama Bin Laden y Abu Muhammed al-Maqdisi. Esto daría origen a un activismo más violento, concentrado en la realización de la yihad contra el imperialismo y contra los gobiernos de los países árabes. De este modo, Al-Qaeda identificaba dos tipos de enemigos: el cercano y el lejano. El primero de estos señala a los gobernantes actuales de ser enemigos del islam, apóstatas e infieles, ya que no aplican plenamente la sharia (violando la soberanía de Dios) y mantienen relaciones con los países occidentales (desatendiendo la obligación de disociarse de los infieles de acuerdo al concepto de al-wala' wa al-bara'20.

\footnotetext{
19 Aquel que se esfuerza o aquel que hace la yihad (Esposito, 2003).

20 Asimismo, es importante destacar el concepto de millat Ibrabim que se desarrolla a partir del Corán 60:4; este señala el ejemplo de Abraham cuando se alejó de su familia y les declaró su enemistad debido a que no aceptaban la unicidad de Dios. Este concepto será parte
} 
Por su parte, la lucha contra el enemigo lejano tiene como objetivo retribuir el sufrimiento y la humillación del pueblo musulmán. Así, Bin Laden señala tres tipos de agravios: el primero es religioso, centrado en la ocupación de las tierras musulmanas; el segundo, económico, denunciando el caos que producen en el mundo musulmán las sanciones y la explotación económica de Occidente; y tercero, vinculando lo económico y lo religioso, señala la "presencia siniestra" de Occidente y del materialismo como fuente del sufrimiento y del alejamiento de los musulmanes de su religión (Kfir, 2015, pp. 236-237). Por lo tanto, este componente de la victimización presentaba las acciones terroristas como actos de yihad defensiva.

Finalmente, el periodo más reciente del discurso salafista se desarrollaría a partir del pensamiento extremista de Abu Musab al-Zarqawi, reconocido por el uso excesivo de la violencia, el antichiismo y su influencia ideológica en el Estado Islámico. Por consiguiente, esta versión "zarqawista" del salafismo se desarrollaría gracias a la invasión estadounidense de Irak (2003) y, posteriormente, a la guerra civil siria (2011). En ambos casos, la situación de la comunidad sunnita se presentaba como parte de una guerra de Occidente, en complicidad con los chiitas, para eliminar la "verdadera religión”. Por tanto, a partir del sentimiento de victimización de los sunnitas se securitizaba el islam.

Aunque al-Zarqawi compartía el antiamericanismo y la lucha contra los regímenes árabes, la excesiva violencia, el antichiismo y el constante señalamiento de takfir establecería un punto de divergencia con Bin Laden (Weaver, 2006). No obstante, a pesar del rechazo que causaba, el "zarqawismo" presentaba una propuesta agresiva para cumplir muchos de los ideales del salafismo yihadista: la lucha contra el enemigo, la implementación de la sharia, la recuperación de la gloria pasada y la restauración del califato.

Así, el primero objetivo consistía en la acción violenta en contra de los infieles e idólatras. Por lo tanto, la yihad ofensiva se realizaba 
contra toda manifestación de shirk, representada en el chiismo y en las minorías; mientras que la yihad defensiva se dirigía contra los gobiernos taghut y Occidente (Bunzel, 2015, p. 10). De este modo, la organización Jama'at al-Tawhid wal-Jihad, fundada por al-Zarqawi, sería reconocida por los atentados contra varios hoteles de lujo en Jordania, el carro bomba contra la sede de la Misión de Naciones Unidas en Irak (UNAMI) y la ejecución del norteamericano Nick Berg. Sin embargo, para la estrategia de la organización, los ataques contra la población chiita tenían mayor relevancia, por lo que las zonas residenciales y altamente transitadas, las plazas de mercado, los cafés y las mezquitas fueron atacadas, siendo las bombas contra las mezquitas del Iman Alí (Najaf 2003) y Al-Askari (Samarra, 2006) los atentados más relevantes. Se buscaba tanto demostrar la incapacidad del gobierno iraquí para ofrecer seguridad y estabilidad como desatar el conflicto sectario entre sunnitas y chiitas (Al-Zarqawi, 2004).

Como segundo aspecto, la implementación férrea de la sharia será un requisito necesario para eliminar todo rastro de idolatría y politeísmo, pero también le permitiría ganar legitimidad al presentarse como defensor de islam más puro. Esto conllevaría, en tercer lugar, a la recuperación de la gloria pasada. En este sentido, la imagen de Nur al-Din Mahmud Zangi, héroe de la segunda cruzada y gobernante de Mosul y Alepo, sería de gran inspiración para al-Zarqawi ${ }^{21}$. Además, es importante recordar que el primer discurso público de Abu Bark al-Baghdadi se realiza desde la mezquita de al-Nuri, en Mosul. Por último, la restauración del califato, para al-Zarqawi, solo era posible a través de una estrategia marcada por la violencia, la cual permitiría desestabilizar los Estados y con ello tomar control territorial hasta transformar las fronteras impuestas por el orden colonial ${ }^{22}$.

\footnotetext{
21 Según señala Saif al-Adel — miembro de Al-Qaeda — la admiración de al-Zarqawi por Nur al-Din —quien liberó la mezquita sagrada de La Meca de los cruzados después de haber iniciado la campaña desde Mosul, y cuya tarea sería culminada por su sucesor, Saladino- motivaría tanto su deseo de iniciar su operación en Irak como su ambición de crear un Estado Islámico (Bunzel, 2015, p. 18; Lahoud, 2014, p. 12).

22 La transformación de las fronteras de Medio Oriente, impuestas por los países europeos a través del tratado de Sykes-Picot, será parte importante del proceso de formación del califato. Así, en el video titulado The Breaking of the Border (junio, 2014), en cual varios
} 
Tabla 2. Periodos de desarrollo del discurso salafista

\begin{tabular}{|c|c|c|c|}
\hline Periodo I & Periodo II & Periodo III & Periodo IV \\
\hline $\begin{array}{l}\text { El islam debe ser } \\
\text { purificado. } \\
\text { Las prácticas que } \\
\text { no correspondan } \\
\text { con el tawhid } \\
\text { deben ser } \\
\text { corregidas y/o } \\
\text { eliminadas. } \\
\text { Es necesaria la } \\
\text { corrección de } \\
\text { la conducta y } \\
\text { el rechazo de } \\
\text { lo no islámico } \\
\text { demostrando la } \\
\text { lealtad a Dios. }\end{array}$ & $\begin{array}{l}\text { La comunidad } \\
\text { musulmana se } \\
\text { encuentra en estado } \\
\text { de ignorancia } \\
\text { (yabiliyyah) y } \\
\text { decadencia. } \\
\text { La soberanía } \\
\text { debe retornar a } \\
\text { Allah a través de } \\
\text { la aplicación de la } \\
\text { sharia. } \\
\text { Se rechaza y } \\
\text { debe realizar la } \\
\text { yihad contra los } \\
\text { gobernantes que no } \\
\text { aplican la sharia y } \\
\text { que toleran prácticas } \\
\text { no islámicas. }\end{array}$ & $\begin{array}{l}\text { Las tierras } \\
\text { musulmanas han } \\
\text { sido invadidas por } \\
\text { infieles y apóstatas } \\
\text { poniendo en } \\
\text { peligro al islam. } \\
\text { Existen dos tipos } \\
\text { de enemigo: } \\
\text { uno cercano (los } \\
\text { gobiernos taghut) } \\
\text { y uno lejano } \\
\text { (Occidente) contra } \\
\text { los cuales se debe } \\
\text { realizar la yihad. } \\
\text { Las humillaciones } \\
\text { y el sufrimiento del } \\
\text { pueblo musulmán } \\
\text { deben ser } \\
\text { retribuidos a través } \\
\text { del ataque a civiles y } \\
\text { a objetivos militares } \\
\text { del enemigo. }\end{array}$ & $\begin{array}{l}\text { Existe una guerra } \\
\text { contra el islam y la } \\
\text { comunidad sunnita. } \\
\text { Los chiitas han } \\
\text { sido cómplices de } \\
\text { la invasión de los } \\
\text { infieles a las tierras } \\
\text { musulmanas. } \\
\text { Se debe realizar la } \\
\text { yihad con el fin de } \\
\text { restaurar el califato, } \\
\text { unificar la umma y } \\
\text { aplicar plenamente la } \\
\text { sharia. }\end{array}$ \\
\hline
\end{tabular}

Fuente: Elaboración propia.

De esta manera, como se observa en la tabla 2, el salafismo yihadista contemporáneo retoma e integra varios elementos de la tradición

miembros del Estado Islámico derrumban la frontera entre Siria e Irak, se señala la unificación de los territorios como el inicio del fin de la humillación del pueblo musulmán y de las innovaciones como el patriotismo y el nacionalismo (Estado Islámico, 2014; Napoleoni, 2015; VICE NEWS, 2014). 
salafista, desde las posiciones teológicas primigenias hasta las políticas del salafismo moderno, marcando el norte para el surgimiento del Estado Islámico y el restablecimiento del califato.

\section{La amenaza al islam y la defensa de la religión para el Estado Islámico}

El discurso salafista es el cimiento para el actuar de grupos como el Estado Islámico, el cual ha securitizado diferentes principios teológicos para justificar desde atentados terroristas y ejecuciones hasta acciones genocidas contra la población no musulmana como yazidíes, cristianos y drusos. De este modo, comprender cómo han sido integrados los planteamientos del salafismo con la securitización de la religión permite reconocer elementos fundamentales para la transmisión y la expansión del mensaje yihadista.

La ideología del Estado Islámico se fundamenta en la defensa del tawhid y en los principios de al-wala' wa al-bara' y al-amr bil-ma'ruf wa'naby'an al-munkar. De este modo, la apelación a la unicidad de Dios como significante dentro del discurso salafista yihadista es la base de la securitización de los grupos extremistas. Como ha señalado la teo-

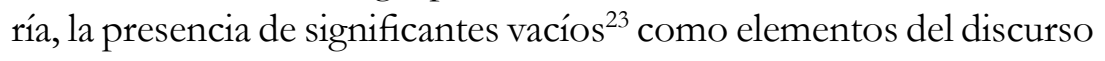
permiten que los actores securitizadores identifiquen las amenazas y enmarquen sus acciones (Sheikh, 2014, p. 268).

Los ataques contra el enemigo tienen motivación religiosa, sin importar si hace referencia a los gobiernos de Occidente, a los kurdos, a al-Assad, a al-Maliki o las minorías. En este sentido, el documento titulado Some of Our Fundamentals, publicado en marzo de 2007, es ilustrativo. En este, el líder del ISI, Abu Omar al-Baghdadi, señala como el objetivo fundamental del grupo la necesidad de destruir

\footnotetext{
23 Los significantes maestros o vacíos corresponden a aquellos conceptos que no poseen un significado dado dentro del análisis del discurso. Estos anudan otros conceptos presentados a las audiencias y enmarcan las acciones a las que apela el actor securitizador. Entre los múltiples significantes, la religión se destaca como uno de los más importantes.
} 
toda manifestación de idolatría y de prohibir todo lo que lleve a ella (Bunzel, 2015, p. 38).

Asimismo, es posible encontrar referencias similares en la revista Dabiq. Por ejemplo, en un artículo titulado Why We Hate You and Why We Fight You que aparece en la decimoquinta edición, el Estado Islámico subraya las razones por las cuales se opone al cristianismo:

Nosotros te odiamos, primero y ante todo, porque son incrédulos; rechazan la unicidad de Allah, ya sea que se den cuenta de ello o no, creando compañeros que son adorados junto a Él, blasfemando contra Él, afirmando que Él tiene un hijo, fabrican mentiras en contra de sus profetas y mensajeros, y se complacen en todo tipo de prácticas diabólicas. [...] así como tu incredulidad es la principal razón por la que te odiamos, tu incredulidad es la principal razón por la que te combatimos, ya que se nos ha ordenado combatir a los incrédulos hasta que se sometan a la autoridad del islam, ya sea convirtiéndose en musulmanes o pagando jiayah — para aquellos que recibieron esta opción- y viviendo en humillación bajo el gobierno de los musulmanes ${ }^{24}$ (Estado Islámico, 2016a, p. 31).

Otro ejemplo, es el artículo titulado The Räfidah: from Ibn Saba' to the Dajjäl, de la decimotercera entrega de la revista, cuyo número está totalmente dedicado a cuestionar los fundamentos doctrinales y teológicos del chiismo. En este se concluye acerca del chiismo que:

Ellos son una secta apóstata que se ahoga en la adoración a los muertos, maldiciendo a los mejores compañeros y esposas del Profeta, sembrando la duda en la base misma de la religión (el Corán y la Sunna), difamando el honor del Profeta, y prefiriendo sus "doce" imanes sobre los profetas e, incluso, ¡Allah! Sus hordas de seguidores participan en la apostasía de sus jefes y líderes. [...] los Räfidah no solo rechazaron a Abū Bakr y a 'Umar, sino que también rechazaron al islam y la base misma de la religión. A lo

24 Traducción libre del autor. 
largo de la historia, nunca han dudado en cooperar con los judíos, los cristianos y los paganos contra el islam y los musulmanes ${ }^{25}$ (Estado Islámico, 2016, p. 45).

De esta manera, a partir de la justificación religiosa, se desarrolla la secuencia narrativa que el Estado Islámico presenta en la propaganda; por ejemplo, en sus videos se observa, en líneas generales, la alternancia de la citación del Corán y los hadices con imágenes de los bombardeos de la coalición internacional, el sufrimiento de la población sunnita y la ejecución del enemigo. Así ocurre en videos como Flames of War, The Expedition of Prisoners o Healing of the Believers' Chests. Este último recordado por presentar la ejecución del piloto jordano Muadh al-Kasasbeh. Por consiguiente, esta forma de transmitir el discurso ha permitido lograr, en una misma producción, atemorizar al enemigo, adquirir legitimidad y reclutar combatientes de forma simultánea.

Asimismo, la extrema violencia y su representación se han convertido en un elemento fundamental y subsecuente de la justificación religiosa. De este modo, el Estado Islámico ha puesto en práctica los postulados de Abu Bark Naji en su texto Management of Savagery (Idarat al-Tawahush), distribuido dentro de los miembros de la organización (Hassan, 2015), y reconocido como el fundamento y el manual que siguen los yihadistas para la realización de sus acciones más atroces.

Según William McCants (2015, p. 82), este explica cómo tomar el control del territorio, establecer un "Estado" y desarrollarlo hasta crear un califato. Así, Naji señala que a través de campañas sostenidas de extrema violencia se logra desgastar al enemigo, lo que desencadena la aparición de vacíos seguridad (o "regiones de salvajismo") que deben ser ocupados por los yihadistas y para estabilizarlos al ofrecer los servicios básicos, bienes públicos y de seguridad de acuerdo al gobierno de la sharia (McCants, 2015, p. 83). Esta estrategia tiene bastantes similitudes tanto con el documento denominado Strategic Plan for Reinforcing the Political Position of the Islamic State in Iraq - que

25 Traducción libre del autor. 
circuló a inicios de 2010 - como con la denominada "Metodología profética", diseñada por al-Zaraqawi y presentada en el primer número de Dabiq.

Sin embargo, uno de los aportes importantes de Management of Savagery a la ideología del Estado Islámico es la concepción de la yihad (Hassan, 2015), que debe ser brutal, inmisericorde y violenta con los enemigos:

Aquellos que estudian la yihad teórica, es decir, que estudian solo la yihad tal como está escrita en papel, nunca comprenderán bien este punto. Lamentablemente, los jóvenes de nuestra umma, desde el momento en que fueron despojados de las armas, ya no entienden la naturaleza de las guerras. Quienes previamente participaron en la yihad saben que no es más que violencia, crudeza, terrorismo, atemorizar (a los otros) y masacre. Estoy hablando de yihad y lucha, no sobre el islam y no deberían confundirse. [...] Además, no puede continuar la yihad con suavidad, ya sea que la suavidad esté en el modo de invitar a otros a unirse (a la yihad), tomar posiciones o (emprender) las operaciones, ya que el ingrediente de la suavidad es uno de los ingredientes de fracaso para cualquier acción yihadista ${ }^{26}$ (Naji, 2006, p. 72).

Por lo anterior, la yihad es activa, se aleja de los extensos y largos sermones y fatwas teóricas presentadas por Al Qaeda. Además, al hacer referencia a las historias - cruentas - de los primeros musulmanes, presenta una yihad que va más allá del "papel" (Hassan, 2015), aspecto vital para el reclutamiento de jóvenes (extranjeros).

Por otra parte, la violencia y la brutalidad tienen como fin intimidar y disuadir al enemigo. Así, señala Naji: "[i]ndependientemente de si usamos dureza o suavidad, nuestros enemigos no serán misericordiosos con nosotros si nos atrapan. Por lo tanto, nos corresponde hacerlos pensar mil veces antes de atacarnos ${ }^{27 ”}$ (Naji, 2006, p. 72). De este modo,

26 Traducción libre del autor. 
acciones como la decapitación, la crucifixión o la incineración buscan impactar en la voluntad de los enemigos y hacerles "pagar el precio" por las humillaciones que el pueblo musulmán ha sufrido, ganando simpatizantes y voluntarios a su causa.

En segundo lugar, para el Estado Islámico, el sentimiento de victimización de la comunidad musulmana es un aspecto fundamental para la identidad del grupo, pues le permite presentarse como defensor y libertador de los sunnitas ante unos gobiernos chiitas opresores. Por esta razón, a medida que aumentaba la represión de las protestas que surgieron entre 2011 y 2012, en Irak y Siria, el Estado Islámico resaltaba sus operaciones militares como parte de la yihad en contra del enemigo chiita.

De este modo, a la par del crecimiento en Siria, la campaña del Estado Islámico — para entonces ISIS — en Irak se intensificaba. Gran parte de esta ofensiva fue registrada en video y puso en evidencia la superioridad sobre las fuerzas de seguridad, no solamente producto de la capacidad militar, sino además de la "bendición divina", pues se resaltaban las victorias de un puñado de hombres contra cientos o miles de miembros del ejército iraquí. Estos videos eran un registro del avance territorial: se documentaron las conquistas de Faluya, Raqqa, Mosul, Samarra, Tikrit, entre otras ciudades.

Por otro lado, en los videos también se destacaban las reacciones de la población tras la conquista de las ciudades. Los combatientes de ISIS se presentaban como libertadores al mostrar cómo su llegada era celebrada por la población (International Crisis Group, 2014, p. 2). No obstante, el escalamiento de la violencia entre los manifestantes y los gobiernos fue fundamental y, a medida que se hicieron más sangrientos los choques, el Estado Islámico se convirtió en una fuente de estabilidad, gobernabilidad y seguridad. Aunque muchos sunnitas no se encontraban de acuerdo con sus postulados teológicos, el Estado Islámico era considerado un mal necesario para la defensa de sus intereses y de su seguridad. 
En este punto, es importante señalar el papel de la propaganda como herramienta para el reclutamiento de combatientes y para la transmisión del mensaje salafista. Dentro de esta, presentar el sufrimiento sunnita como parte de una guerra entre el "bien" y el "mal" fue un elemento destacado para el crecimiento del grupo. Ciudadanos iraquíes, árabes y de países europeos se unieron a las filas del Estado Islámico con el fin de hacer frente a los infieles y terminar con el sufrimiento de sus correligionarios. A esto se sumaba cierta "mística" introducida a través de narraciones apocalípticas y referencias a un pasado glorioso. Así, muchos de estos hombres consideraban que estaban librando las primeras batallas del fin de los tiempos.

Por último, a partir de la identidad del islam, la ideología salafista del Estado Islámico estrecha el mercado de identidades/religiones al presentar una visión de mundo y del "buen musulmán" para ser acep$\operatorname{tada}^{28}$. Por consiguiente, recurre a los principios de al-amr bi'l-ma'ruf wa'-naby'an al-munkar y al-wala' wa al-bara' para movilizar a los musulmanes hacia la realización de la yihad y a la adhesión a su proyecto.

El principio de al-amr bi'-ma'ruf wa'l-naby'an al-munkar es aplicado como parte de la estrategia de gobernanza del Estado Islámico. La bisba — llamada "la policía religiosa" - se encarga de establecer y mantener la legitimidad religiosa (Caris \& Reynolds, 2014, p. 16) corrigiendo el comportamiento de los musulmanes al hacerlo acorde a la sharia. Sus actividades incluyen la quema de cigarrillos, drogas y alcohol; la destrucción de tumbas y santuarios que fomenten el politeísmo; garantizar el cumplimiento de la oración; controlar los precios al consumidor; y la implementación de los castigos buddud que incluyen azotes, la crucifixión, la amputación y la decapitación

\footnotetext{
28 Kfir (2015) asocia el concepto de economía de la religión con la teoría de la identidad social, con lo cual reconoce al Estado Islámico como un productor de la religión que busca generar un mensaje que no puede ser rechazado por los individuos. La receptividad de este mensaje está influenciada por los contextos que le permiten al productor ofrecer bienes y servicios — tangibles e intangibles - para lograr la movilización de los simpatizantes (p. 236). De este modo, el Estado Islámico se presenta como defensor del verdadero islam y como proveedor de seguridad y estabilidad ante la situación de los musulmanes en Medio Oriente (p. 242).
} 
(Zelin, 2016, pp. 3-4). El cumplimiento de estas tareas ha sido resaltado constantemente en la propaganda del Estado Islámico como se observa en los videos The Best Ummah (mayo de 2014) o Men of the Hisbah (junio de 2015).

Por su parte, el concepto de al-wala' wa al-bara' señala la división entre el islam y la idolatría y el politeísmo, por tanto, las prácticas y el actuar del musulmán deben preservar la pureza del islam y mostrar la lealtad a Allah al rechazar y enfrentar al enemigo. Esto ha sido utilizado por el Estado Islámico para justificar la migración hacia el autoproclamado califato. La disposición a disociarse de los infieles se evidenciará al abandonar dar al-Kufr (la tierra de los infieles) para establecerse en dar al-Islam (Wagemakers, 2008, p. 7).

Asimismo, como muestra de al-wala' (lealtad) ante la guerra de los "cruzados" contra el mundo musulmán, atacar a los ciudadanos de Occidente representa un deber obligatorio para retribuir la humillación, como ha señalado en uno de sus discursos al-Adnani, vocero de la organización ${ }^{29}$. Finalmente, tras la proclamación del califato, la mayor muestra de lealtad es la eliminación de toda representación de shirk de las tierras del islam, por lo que las minorías se convierten en un objetivo.

29 En el discurso Indeed Your Lord Is Ever Watchful, al-Adnani (2014) señala:

¡Oh muyahidín... Oh tú quien cree en walā’ y barā'... ¿dejarán al estadounidense, al francés o a cualquiera de sus aliados caminar con seguridad sobre la tierra mientras los ejércitos de los cruzados golpean las tierras de los musulmanes sin diferenciar entre un civil y un luchador? Han matado a nueve mujeres musulmanas hace tres días golpeando un autobús que las transportaba de Shām a Irak. ¿Dejarás al incrédulo dormir tranquilo en casa mientras las mujeres y los niños musulmanes tiemblan de miedo con los rugidos de los aviones cruzados por encima de sus cabezas día y noche? ¿Cómo puedes disfrutar de la vida y del sueño mientras no ayudas a tus hermanos, ni llenas miedo los corazones de los adoradores de la cruz, y ni devuelves sus ataques multiplicándolo? (p. 12)[traducción libre del autor]. 


\section{El califato y las minorías}

A inicios julio de 2014, el líder del Estado Islámico, Abu Bark alBaghdadi, hacía su primera — y única - aparición pública para proclamar la reinstauración del califato. A partir de entonces, se pondría en marcha una campaña sistemática para eliminar la presencia de las minorías, consideradas una representación del politeísmo y la idolatría. Como señalaría la revista Dabiq en el caso de los yazidíes:

Su continua existencia hasta estos días es un asunto por el que los musulmanes deberán responder en el Día del Juicio, considerando que Allah ha revelado el Ayyat as-Sayf (el verso de la espada) hace más de 1400 años. El glorificado dijo, \{mas cuando hayan pasado los meses sagrados matad a los idólatras dondequiera les halléis [cursiva agregada], capturadles, cercadles y tendedles emboscadas en todo lugar, pero si se arrepienten [y aceptan el islam], cumplen con la oración prescrita y pagan el Zakât dejadles en paz. Ciertamente Allah es Absolvedor, Misericordioso\} [Al Barâ’ah: 5] ${ }^{30}$ (Estado Islámico, 2014a, p. 14).

Entre los meses de julio y septiembre de 2014, el Estado Islámico avanzaría sobre la provincia de Nínive para consolidar su dominio e instaurar la sharia. Para las minorías, esto significaría la mayor amenaza existencial que enfrentarían hasta el momento. Si bien estas se encontraban en una situación precaria, producto de la violencia sectaria y la disputa entre los gobiernos kurdo e iraquí, el avance del Estado Islámico sobre Sinjar y la Llanura de Nínive fue devastador.

El distrito de Sinjar fue atacado en los primeros días de agosto. Allí se concentraba la mayoría de la población yazidí que habitaba estos territorios desde el año 4000 a. C., aproximadamente. (Minority Rights Group International, 2015, p. 9). Esta minoría ha sido acusada de ser adoradora del demonio, por lo que ha sido perseguida históricamente $^{31}$. Asimismo, era señalada de fomentar prácticas no islámicas

\footnotetext{
30 Traducción libre del autor.

31 Melek Ta'us es el centro del culto de la fe yazidí. Sin embargo, este es uno de los siete ángeles que son alabados en esta religión (Ahram, 2014; Yazda \& the Free Yezidi Foundation,
} 
debido a que — junto con los cristianos — tenían permitido dedicarse a la venta de alcohol.

En este orden de ideas, como señalaría la revista Dabiq, previamente al avance sobre Sinjar y Zumar, los yazidíes fueron estudiados por el departamento de la sharia del Estado Islámico, el cual concluyó que deberían ser tratados como mushirk (politeístas); por esta razón, no pueden acceder al pago de la jizyah, sus mujeres podrían ser esclavizadas y solo tienen la opción de elegir entre la conversión o la muerte (Estado Islámico, 2014a, p. 15). Por consiguiente, los ataques del Estado Islámico tendrían como objetivo eliminar la identidad yazidí.

Las poblaciones de Sinjar, Zumar, Kocho, Qiniyeh, Hardan, Khana Sor, Solagh y Jdali fueron el escenario de la ejecución de centenares de hombres y del secuestro masivo de miles de yazidíes, principalmente mujeres y niños, entre el 3 y el 15 de agosto de 2014. Algunas cifras estiman que 1562 yazidíes murieron durante la ofensiva del Estado Islámico, 5838 fueron secuestrados, de los cuales eran 3192 mujeres (The 21 st Century Wilberforce Initiative, 2015, p. 21). Hoy en día, a falta de cifras concretas, se calcula que entre 2500 y 3000 personas permanecen secuestradas (Human Rights Council, 2016, p. 4; The United State Holocaust Memorial Museum, 2015, p. 21).

En consecuencia, se produjo el desplazamiento de aproximadamente 850 mil personas (Amnistía Internacional, 2014, p. 4). Cerca de 50 mil, de forma desesperada, buscaron refugio en el escabroso monte Sinjar. Allí, fueron sitiadas durante cerca de dos semanas y debieron soportar altas temperaturas, sin agua, comida ni medicamentos ${ }^{32}$. Al

2015, pp. 8-9). Según la tradición, Dios ordenó a los ángeles que le oraran, a lo que Melek Ta'us se opuso, provocando su expulsión del cielo. Aunque posteriormente fue perdonado por Dios y encargado de ejecutar/proteger su creación (Taneja, 2007, p. 13), para musulmanes y cristianos esta es la representación del demonio.

32 Es recordado el discurso del 5 agosto de 2014 de la representante yazidí en el parlamento iraquí, Vian Dakhil, en el cual suplicaba, en medio del llanto, la intervención de la comunidad internacional para detener el avance del Estado Islámico en el monte Sinjar. De este modo, en el video que se conoció a través YouTube, Dakhil denunciaba el genocidio que se estaba cometiendo en contra de su pueblo. Según señaló el propio presidente esta- 
menos 500 yazidíes murieron, entre ellos 40 niños (Minority Rights Group International, 2015, p. 13). Para el Estado Islámico, este era un justo castigo por no haber aceptado la conversión al islam, como se señaló en un video divulgado a mediados de agosto, en el cual se entrevistaba a uno de los comandantes de la operación sobre Sinjar, quien invitaba a los yazidíes a elegir entre el islam o la muerte en la montaña (Estado Islámico, 2014b).

Sin embargo, el mayor intento por erradicar y asimilar a la comunidad yazidí fue la violencia sexual. De este modo, las mujeres y niñas mayores de nueve años fueron consideradas botín de guerra (malak yamiin) para ser repartido entre los miembros de la organización (Amnistía Internacional, 2014a). Según el Estado Islámico, estas acciones hacían parte de la recuperación de una tradición musulmana, utilizada por el Profeta, denominada saby o sabiya, que consiste en esclavizar a las mujeres de los kuffar capturadas en las guerras. Esta es considerada parte de la sharia, razón por la cual el Departamento de Proclamación de Fatwas e Investigación (Diwan al-'Iftaa wa al-Bubuth) del Estado Islámico publicó diferentes documentos para justificar y reglamentar esta práctica. En estos se autorizaba la toma de sabiyas como parte de la yihad para la expansión del islam y para la lucha contra los infieles (Al-Tamimi, 2015; 2015a).

Estos hechos han causado un efecto devastador sobre los yazidíes. No solamente por el impacto inmediato que causa el secuestro y el abuso sexual de las mujeres en la comunidad, sino también por el impacto psicológico y la ruptura del tejido social que produce el estigma que recae sobre las víctimas. Inclusive los líderes religiosos se han visto en la necesidad de emitir decretos que ordenan dar la bienvenida a las mujeres liberadas por el Estado Islámico (Graham-Harrison, 2017; Minority Rights Group International, 2015, p. 16). El impacto de la violencia sexual en la fábrica social de la comunidad trasciende en el corto y en el largo plazo.

dounidense, Barack Obama, la emotiva petición de Dakhil influyó en su decisión de iniciar los bombardeos estadounidenses en contra del Estado Islámico a partir del 8 de agosto (Haworth, 2015). 
Por otro lado, a pesar de soportar años de persecución y acoso, el avance del Estado Islámico sobre Mosul, Qaraqosh y demás pueblos de la Llanura de Nínive significaría para los cristianos la expulsión de sus tierras ancestrales y el mayor intento por erradicar su identidad. El ultimátum para convertirse al islam, pagar la jizy $a b^{33}$ o ser asesinados, dejó como última opción a los habitantes marcharse de las ciudades. De este modo, aproximadamente 200 mil personas huyeron hacia el Kurdistán iraquí (Minority Rights Group International, 2014, p. 9).

El desarraigo de las tierras que habían ocupado desde hace miles de años afectaba la existencia de su identidad, dejando a merced de los yihadistas la riqueza cultural de las primeras comunidades cristianas. La confiscación de las propiedades y las pertenencias de los cristianos hizo aún más humillante el abandono de las ciudades. De este modo, el Estado Islámico instaló puestos de control en las afueras de las poblaciones, en donde las personas eran obligadas a entregar el dinero, los documentos de identificación, las joyas y los objetos de valor; también los vehículos fueron confiscados, obligando a quienes huían hacia Kurdistán a continuar su camino a pie (Barber, 2016, p. 467; Minority Rights Group International, 2014, p. 20).

Igualmente, las viviendas, iglesias y edificios pertenecientes a los cristianos fueron marcados con la letra "N" de nazareno (Nasrani) y la leyenda de "propiedad del Estado Islámico" (Minority Rights Group International, 2014, p. 20; Shamdeen, 2015). Las propiedades cristianas inscritas en el Registro de Bienes Raíces y en otras instituciones gubernamentales fueron expropiadas, mientras que a los

\footnotetext{
33 Impuesto sobre la gente del libro (Ahl al-Kitâb o dhimmis) que vive bajo el dominio de los musulmanes. Este denominado "pacto dhimmi" o "pacto de Omar" (en referencia al segundo califa) implicaba duras condiciones para aquellos cristianos que lo aceptaran. Como señalaría la revista Dabiq, en su decimoquinta edición, la aceptación significaba el reconocimiento de la inferioridad y la humillación ante los musulmanes, por lo que no se podrían construir nuevos templos o monasterios; ni reparar los daños sufridos; ni impedir que los musulmanes usen sus edificios como refugios; no deberán albergar espías ni enemigos; no deberán mostrar sus prácticas paganas en público ni invitar a alguien a ellas; no deberán impedir que algún familiar adopte el islam; no podrán portar armas; no venderán vino; no podrán colocar cruces en las iglesias ni a la vista de algún musulmán; ni podrán levantar la voz durante sus oraciones en los templos; entre otras (Estado Islámico, 2016b, p. 63).
} 
musulmanes que hubieran rentado a los cristianos se les indicó que, en adelante, deberían hacer el pago al grupo (Shamdeen, 2015). Por último, en las calles de Mosul, se estableció un mercado de segunda mano denominado "Botín de los Nasrani" en el que se ofrecían los electrodomésticos, muebles y demás objetos robados de los hogares y templos cristianos (Williams, 2015).

Sin embargo, para al-Baghdadi, el establecimiento del pacto dhimmi era una parte importante del cumplimiento de la ley islámica. Por esta razón, en todas aquellas poblaciones cristianas que controlaba, tanto en Siria como en Irak, el Estado Islámico buscó imponerlo. En parte de su propaganda se publicitaba la aceptación del pacto por parte de los cristianos de Raqqa y de otras partes de Siria. Los cristianos iraquíes ni siquiera consideraron esta posibilidad al observar las acciones del Estado Islámico durante sus primeros días de gobierno en Mosul. Además, era imposible reunir la cantidad de dinero exigida con las reglas impuestas, pues impedían que se obtuvieran ingresos (Barber, 2016, pp. 469-473).

La mayoría — por no decir, la totalidad — de la población cristiana abandonó las ciudades de Mosul, Tel Kaif y Qaraqosh; para finales de 2014, la población cristiana había prácticamente desaparecido de las tierras que habían ocupado durante milenios. Como señalaría el arzobispo de Erbil, Bashar Barda, el 15 de junio de 2014 fue la primera vez en 1600 años que la misa no se celebró en Mosul (Minority Rights Group International, 2014, p. 9).

\section{Conclusión}

El discurso salafista ha evolucionado de acuerdo a los desarrollos contextuales. Formulado a partir de principios teológicos, los sucesos históricos en Medio Oriente han permitido generar el ambiente para que las ideas radicales encuentren asidero entre la población musulmana. A través de la experiencia colonial y el intervencionismo estadounidense en la región se han politizado y securitizado los planteamientos del salafismo. 
Como una corriente del islam que prioriza la acción sobre la creencia, las bases teológicas de tawhid, al-amr bi'l-ma'ruf wa'l-naby'an al-munkar y al-wala' wa al-bara' han encontrado en la violencia el método ideal para la defensa de la concepción prístina del islam. Asimismo, estos conceptos han permitido que el discurso del salafismo yihadista pueda diferenciar entre lo que es musulmán y lo que no, identificando a los enemigos de la religión contra los cuales se debe actuar.

La securitización de la religión que realiza el Estado Islámico — como heredero de la tradición salafista - se expresa como una dinámica de seguridad tanto ofensiva como defensiva. Inicialmente defensiva, siendo su objetivo defender la pureza del islam ante las amenazas provenientes de infieles, apóstatas e idólatras; y por otro lado, ofensiva, exigiendo el actuar urgente en contra de todo aquello que impida o pueda impedir la vivencia de la verdadera religión.

Por lo anterior, la defensa de la religión, a partir del discurso salafista, implica el desarrollo de una identidad —el "islam verdadero", el pueblo sunnita y el "buen musulmán"- que se contrapone existencialmente a la presencia de otras comunidades religiosas. Por consiguiente, las minorías han sido llevadas al borde del exterminio.

\section{Referencias}

Ahram, A. (2014). Can ISIS overcome the insurgency resource curse? En Project on Middle East Political Science, Iraq Between Maliki and the Islamic State, pp. 29-31. POMEPS Briefing 24. Recuperado el 29 de diciembre de 2015 de https://pomeps.org/2014/07/09/iraq-between-malikiand-the-islamic-state/

Al-Adnani, A. M. (22 de septiembre de 2014). Indeed your lord is ever watchful. Recuperado el 15 de enero de 2017 de https://archive.org/details/ IndeedYourLordIsEverWatchful

Al-Tamimi, A. J. (26 de febrero de 2014). The Islamic State of Iraq and ashSham's dhimmi pact for the Christians of Raqqa province. Recuperado el 14 de marzo de 2017 de Aymenn Jawad Al-Tamimi http:/ /www.aymennjawad.org/14472/the-islamic-state-of-iraq-and-ash-sham-dhimmi 
Al-Tamimi, A. J. (29 de diciembre de 2015). Unseen Islamic State pamphlet on slavery. Recuperado el 12 de enero de 2016 de Aymenn Jawad AlTamimi http://www.aymennjawad.org/2015/12/unseen-islamicstate-pamphlet-on-slavery

Al-Zarqawi, A. M. (febrero de 2004). Zarqawi letter. English translation of terrorist Musab al Zarqawi letter obtained by United States Government in Iraq. Recuperado el 13 de enero de 2017 de U. S. Deparment of State https://2001-2009.state.gov/p/nea/rls/31694.htm\#

Amnistía Internacional. (2014). Ethnic cleansing on historic scale: The Islamic State's systematic targeting of minorities in northern Iraq. Recuperado el 2 de diciembre de 2015 de https://www.amnesty.org/es/documents/ mde14/011/2014/en/

Amnistía Internacional. (2014a). Escape from hell. Torture and sexual slavery in Islamic State captivity in Iraq. Recuperado de https:/ / www.amnesty.org. $\mathrm{uk} /$ sites/default/files/escape_from_hell_-_torture_and_sexual_slavery_in_islamic_state_captivity_in_iraq_-_english_2.pdf

Barber, M. (2016). They that remain: Syrian and Iraqi Christian communities amid the Syria conflict and the rise of the Islamic State. En A. D. Hertzke \& T. S. Shah (Eds.), Cristianity and freedom, Vol. II (pp. 453488). Cambridge: Cambridge University Press.

Bunzel, C. (2015). From paper state to caliphate: The ideology of the Islamic State. Analysis Paper $N^{\circ}$ 19, The Brookings Project on U. S. relations with the Islamic World. Washington: Center for the Middle East Policy at The Brookings Institution. Recuperado el 14 de septiembre de 2016 de https://www.brookings.edu/wp-content/uploads/2016/06/Theideology-of-the-Islamic-State.pdf

Buzan, B., Waever, O. \& de Wilde, J. (1998). Security: A framework for the analysis. Londres: Lynne Rienner Publishers.

Caris , C. \& Reynolds, S. (2014). ISIS governance in Syria. Middle East report $N^{\circ} 22$. Washington: Institute for the Study of the War. Recuperado el 24 de ocubre de 2015 de http:/ / www.understandingwar.org/report/ isis-governance-syria

El-Affendi, A. (2010). Umma, State and movement: Events that shaped the modern debate. En K. Hroud (ed.), Political Islam: Context versus ideology, pp. 20-36. Londres: SAQI \& London Middle East Institute SOAS. 
Esposito, J. L. (Ed.). (2003). Oxford dictionary of Islam. Oxford: Oxford University Press. Recuperado de http:/ /www.oxfordislamicstudies.com/ browse?type $=$ article

Estado Islámico. (29 de junio de 2014). The breaking of the border. (alI'tişām Media) Recuperado el 13 de octubre de 2015 de Jihadology http://jihadology.net/2014/06/29/al-iti\%E1\%B9\%A3am-mediapresents-a-new-video-message-from-the-islamic-state-of-iraq-andal-sham-breaking-of-the-border/

Estado Islámico. (2014a). The revivial of slavery before the hour. Dabiq, (4), 14-18. Recuperado el 4 de marzo de 2015 de https:/ /azelin.files. wordpress.com/2015/02/the-islamic-state-e2809cdc481biq-magazine-422.pdf

Estado Islámico. (20 de agosto de 2014b). Entry of hundreds of yazidis to Islam. Recuperado el 5 de diciembre de 2015 de Jihadology http:/ / jihadology.net/2014/08/20/new-video-message-from-the-islamicstate-entry-of-hundreds-of-yazidis-to-islam-wilayat-ninawa/

Estado Islámico. (2016). The rafidah. From Ibn Saba' to the Dajjal. Dabiq, (13), 32-45. Recuperado el 4 de marzo de 2016 de http://jihadology. net/2016/01/19/new-issue-of-the-islamic-states-magazine-dabiq-13/

Estado Islámico. (2016a). Why we hate you and why we fight you. Dabiq, (15), 30-33. Recuperado el 13 de noviembre de 2016 de http:/ jihadology. net/2016/07/31/new-issue-of-the-islamic-states-magazine-dabiq-15/

Estado Islámico. (2016b). Break the cross. Dabiq, (15), 46-63. Recuperado el 9 de abril de 2017 de http://jihadology.net/2016/07/31/new-issueof-the-islamic-states-magazine-dabiq-15/

Graham-Harrison, E. (1 de julio de 2017). "I was sold seven times": The Yazidi women belcomed Back into the faith. Recuperado el 13 de julio de 2017 de The Guardian https:/ /www.theguardian.com/globaldevelopment/2017/jul/01/i-was-sold-seven-times-yazidi-womenwelcomed-back-into-the-faith

Hassan, H. (8 de febrero de 2015). Isis has reached new depths of depravity. But there is a brutal logic behind it. Recuperado el 19 de diciembre de 2017 de The Guardian https:/ /www.theguardian.com/world/2015/ feb/08/isis-islamic-state-ideology-sharia-syria-iraq-jordan-pilot

Haworth, A. (8 de febrero de 2015). Vian Dakhil: Iraq's only female Yazidi MP on the battle to save her people. Recuperado el 15 de marzo de 
2017, de The Guardian https://www.theguardian.com/world/2015/ $\mathrm{feb} / 08 /$ vian-dakhil-iraq-isis-yazidi-women

Helfont, S. (2009). The Sunni divide: Understanding politics and terrorism in the Arab Middle East. Philadelphia: Foreign Policy Research Institute. FPRI's Center on Terrorism and Counterterrorism. Recuperado el 26 de diciembre de 2015 de http:/ /www.fpri.org/docs/media/Helfont. SunniDivide.pdf

Human Rights Council. (2016). "They came to destroy": IsIs crimes againts the Yazidies. United Nations. Recuperado el 20 de junio de 2016 de http://www.ohchr.org/Documents/HRBodies/HRCouncil/ CoISyria/A_HRC_32_CRP.2_en.pdf

Human Rights Watch. (30 de octubre de 2014). Iraq: IsIS executed hundreds of prison. Recuperado el 28 de diciembre de 2015 de Human Rights Watch https://www.hrw.org/news/2014/10/30/iraqisisexecutedhundredsprisoninmates

International Crisis Group. (2014). Iraq's Jihadi Jack-in-the-Box. Middle East briefing $N^{\circ} 38$, Beirut/Brussels. Recuperado el 11 de noviembre de 2016 de https:/ / www.crisisgroup.org/middle-east-north-africa/gulfand-arabian-peninsula/iraq/iraq-s-jihadi-jack-box

Kfir, I. (2015). Social identity group and human (in)security: The case of Islamic State in Iraq and the Levant (ISIL). Studies in Conflict \& Terrorism, 38(4), 233-252. Doi: http://doi.org/10.1080/1057610X.2014.997510

Lahoud, N. (2014). Metamorphosis: From al-Tawhid wa-al-Jihad to Dawlat al-Khilafa (2003-2014). En M. Al-'Ubaydi, N. Lahoud, D. Milton \& B. Price, The group that calls itself a state: Understanding the evolution and challenges of the Islamic State, pp. 8-26. West Pointy: The Combating Terrorism Center at West Point. Recuperado el 19 de octubre de 2016 de https://www.ctc.usma.edu/posts/the-group-that-calls-itself-astate-understanding-the-evolution-and-challenges-of-the-islamic-state Laustsen, C. B. \& Waever, O. (2003). In defense of religion. Sacred referent objects for securitization. En F. Petito \& P. Hatzopoulos (Eds.), Religion in international relations. The return from exile (pp. 147-180). New York: Palgrave Macmillan.

McCants, W. (2015). The ISIS apocalypse. The history, strategy, and doomsday vision of the Islamic State. New York: Saint Martin's Press. 
Meijer, R. (2010). Salafism: Doctrine, diversity and practice. En K. Hroud (Ed.), Political Islam. Context versus ideology (pp. 37-60). Londres: SAQI \& London Middle East Intitute SOAS.

Minority Rights Group International. (2014). From crisis to catastrophe: The situation of minorities in Iraq. Recuperado el 29 de junio de 2016 de http://minorityrights.org/publications/from-crisis-to-catastrophethe-situation-of-minorities-in-iraq-october-2014/

Minority Rights Group International. (2015). Between the millstones: The state of Iraq's minorities since the fall of Mosul. Brussels: IILHR, MRG, NPWJ \& UNPO. Recuperado el 31 de agosto de 2016 de http://minorityrights. org/wp-content/uploads/2015/03/MRG_Rep_Iraq_ONLINE.pdf

Naji, A. B. (2006). The management of savagery: The most critical stage through wich the umma will pass. (W. McCants, Trans.) Recuperado el junio 9 de 2016 de https:/ /azelin.files.wordpress.com/2010/08/abu-bakr-najithe-management-of-savagery-the-most-critical-stage-through-whichthe-umma-will-pass.pdf

Napoleoni, L. (2015). El fénix islamista. Barcelona: Paidós.

Olidort, J. (2015). The politics of "quietist" salafism. Analysis paper $N^{\circ} 18$, The Brookings Project on U. S. Relations with the Islamic World. Washington: Certer for the Middle East Policy at the Brookings Institution. Recuperado el 7 de septiembre de 2015 de https://www.brookings.edu/ wp-content/uploads/2016/07/Brookings-Analysis-Paper_JacobOlidort-Inside_Final_Web.pdf

Shamdeen, N. (24 de septiembre de 2015). Islamic State had been harassing Mosul's Christians for years. Recuperado el 24 de noviembre de 2015 de Niqash http://www.niqash.org/en/articles/security/5110/

Sheikh, M. K. (2014). The religious challenge to securitisation theory. Millenium: Journal of International Studies, 43(1), 252-272.

Taneja, P. (2007). Assimilation, exodus, eradication: Iraq's minority communities since 2003. Minority Rights Groups International. Recuperado el 19 de octubre de 2016 de http:/ / www.aina.org/reports/mrgi0702.pdf The $21^{\text {st }}$ Century Wilberforce Initiative. (2015). Edge of extinction. The eradication of eeligious and ethnic minorities in Iraq. Recuperado el 29 de junio de 2016 de http://www.21wilberforce.org/am-site/media/edge-ofextinctionfinal.pdf

The United State Holocaust Memorial Museum. (2015). "Our generation has gone". The Islamic State's targeting of Iraq minorities in Ninewa. Bearing 
Witness Trip Report. Recuperado el 5 de julio de 2016 de https:// www.ushmm.org/m/pdfs/Iraq-Bearing-Witness-Report-111215.pdf

VICE NEWs. (13 de agosto de 2014). Bulldozing the border between Iraq and Syria: The Islamic State. Recuperado de https://youtu.be/ TxX_THjtXOw

Wagemakers, J. (2008). Framing the "threat to Islam": al-wala' wa al-Bara' in Salafi discurse. Arab Studies Quarterly, 30(4), 1-22.

Weaver, M. A. (8 de junio de 2006). The short, violent life of Abu Musab al-Zarqawi. Recuperado el 13 de noviembre de 2016 de The Atlantic: https://www.theatlantic.com/magazine/archive/2006/07/the-shortviolent-life-of-abu-musab-al-zarqawi/304983/

Williams, T. D. (2 de febrero de 2015). IsIs opens market for spoils stolen from Christians in Mosul. Recuperado el 18 de mayo de 2017 de Breitbart http:/ /www.breitbart.com/national-security/2015/02/02/ isis-opens-market-for-spoils-stolen-from-christians-in-mosul/

Yazda \& the Free Yezidi Foundation. (2015). IsIL: Nationals of ICC states parties committing genocide and other crimes against the Yazidis. Recuperado el 26 de diciembre de 2015 de http://www.yazda.org/wp-content/ uploads/2015/09/RED-ISIL-commiting-genocide-against-theYazidis.pdf

Zelin, A. Y. (2016). The Islamic State's territorial methodology. Research notes 29, The Washington Institute for Near East Policy. Recuperado el 1 de mayo de 2016 de http://www.washingtoninstitute.org/policy-analysis/view/ the-islamic-states-territorial-methodology 